\title{
Rotational Symmetry and Corresponding Angle of some Natural Flower Photograph taken by way of my Digital Camera
}

\author{
Amit Kumar Bhunia* \\ Department of Physics, Government General Degree College at Gopiballavpur-II, India
}

Submission: August 19, 2018; Published: September 14, 2018

*Corresponding author: Amit Kumar Bhunia, Government General Degree College at Gopiballavpur-II, Beliaberah, Jhargram-721517, Email: amitphysics87@gmail.com

\begin{abstract}
In this article I mainly focused about different symmetry offers by different kind of flowers surrounding us. I discuss the symmetry of Euphorbia milii, the crown of thorns, Christ plant, or Christ thorn, the Ixora coccinea, the Catharanthus roseus, Coccinia flower, Duranta erecta, Barleria cristata and Adenium flower, Murrayapaniculata commonly called range jessamine. The image of all flower is taken surrounding the midnapore town, West Bengal, India.
\end{abstract}

Keywords: Rotational symmetry; Some flowers; Mirror lines

\section{Mini Review}

Physics and mathematics are all round us. We find out increasingly approximately our environment and our environment we see that nature can be defined mathematically. The splendor of a flower, the majesty of a tree, even the rocks upon which we walk can show off nature's sense of symmetry. Also, symmetry can discover inside the crystal. Radial symmetry is a one of the vital symmetries found inside special plant life. Radial symmetry is rotational symmetry round a set point, called center [1]. In keeping with their symmetry, vegetation is labeled as radially symmetrical or bilaterally symmetrical. Bilateral symmetry, which is idea to have developed from radial symmetry, effects from establishment of asymmetry relative to a dorsoventral axis of flowers.

If an object come into self-coincidence through smallest nonzero rotational angle $\theta$ then it is said to have an $n$-fold rotational axis where $n=360 / \theta, n=2$ called 2 -fold rotational axis, $n=3, n=4$, 5...called four-fold, fivefold so on. Cyclic symmetry is represented with the notation $\mathrm{Cn}$, where $\mathrm{n}$ is the number of rotations. Each rotation will have an angle of $360 / \mathrm{n}$. For example, an object having C3 symmetry would have three rotations of 120 degrees.

Dihedral symmetries fluctuate from cyclic ones in that they've mirrored image symmetry in addition to rotational symmetry. Dihedral symmetries are represented with the notation $\mathrm{Dn}$, wherein $\mathrm{n}$ represents the variety of rotations, as well as the range of mirrored image mirrors gift. each rotation angle could be same to $360 / \mathrm{n}$ diploma and attitude between each replicate can be one hundred eighty/n diploma. An object with D4 symmetry could have 4 rotations, every of ninety levels, and four reflection mirrors, with every angle among them being forty-five degrees. A form with rotational symmetry is a shape that looks the identical even though you turn the form round a bit. Some other way to reflect on consideration on rotational symmetry is to observe inside the following examples how we see several copies organized around a valuable point. Vegetation offers a ramification of radial symmetry. Below the Euphorbia milii, the crown of thorns, Christ plant, or Christ thorn for instance has two leaves arranged around the center of the flower (Figures 1 \& 2).

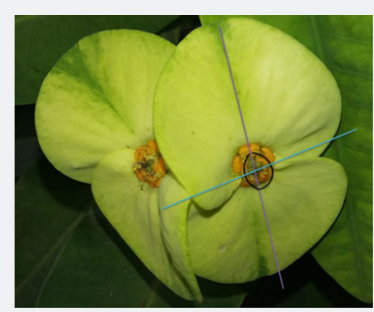

Figure 1: Euphorbia milii, the crown of thorns, Christ plant, or Christ thorn (Two fold symmetry with angle $180^{\circ}$ ).

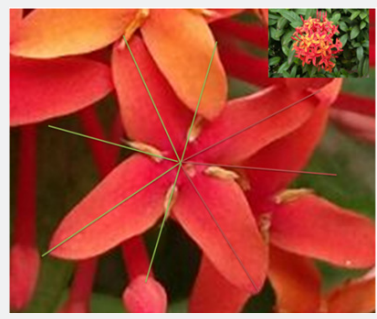

Figure 2: Ixora coccinea (Four-fold symmetry with angle $90^{\circ}$ ). 
The Euphorbia milii, the crown of thorns, Christ plant, or Christ thorn has 2-fold rotational symmetry (180 degrees). The Trillium flower has three long white leaf-like petals with pink marking at the base [2]. It has three-fold rotational symmetry with rotation angle $120^{\circ}$. The Ixora coccinea has 4 legs arranged around the center of the body. This Ixora coccinea has 4 -fold rotational symmetry (90 degrees). The Catharanthus roseus, commonly known as the Madagascar periwinkle, rose periwinkle, or rosy periwinkle, shown here has five equally spaced legs. It has 5-fold rotational symmetry (72 degrees). The Coccinia flower, Duranta erecta, Barleria cristata and Adenium flower (Figure 3) has 5-fold rotational symmetry [3]. Murrayapaniculata commonly called range jessamine has sixfold rotational symmetry (Figure 4). As the lovely rose flower and Canna indica (Figure 5) opens and expands, it suggests a rotational symmetry about its center (Table 1 ) $[5,6]$.
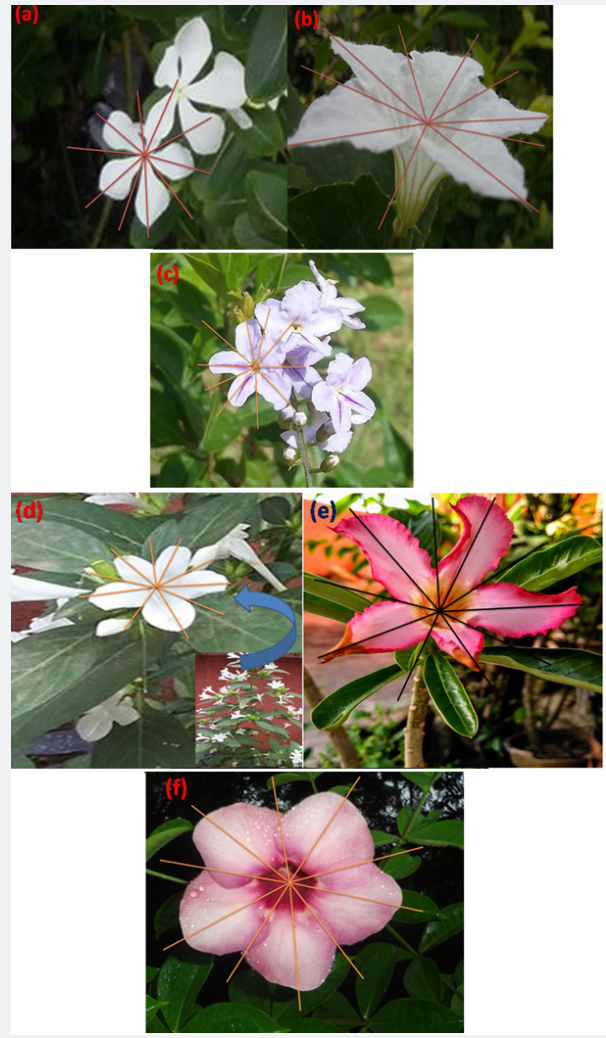

Figure 3: (a) Fivefold symmetry with angle $72^{\circ}$ of Catharanthus roseus. (b) Fivefold symmetry with angle $72^{\circ}$ of Coccinia [4]. (c) Fivefold symmetry with angle $72^{\circ}$ of Duranta erecta. (d) Fivefold symmetry with angle $72^{\circ}$ of Duranta erecta Barleria cristata my image is a Bright White Philippine Violet Alba Barleria Cristata, (e) Fivefold symmetry with angle $72^{\circ}$ of Adenium, (f) Fivefold symmetry with angle $72^{\circ}$ of Summer Romance Vining Pink Mandevilla flowers.

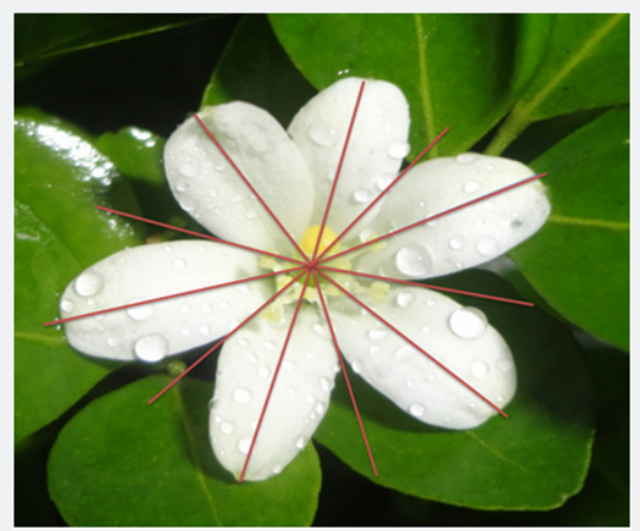

Figure 4: Murrayapaniculata (Six-fold symmetry with angle $60^{\circ}$ and six mirror lines with two are unique). 


\section{Figure 5:}

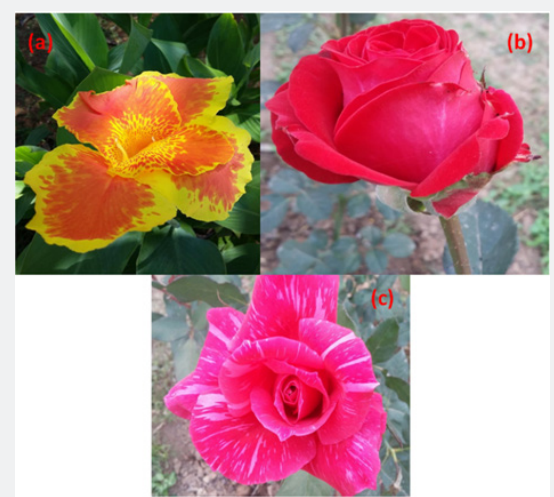
a. Canna indica,
b. Rose 1
c. Rose 2.

Table 1: Symmetry of flowers with angles.

\begin{tabular}{|c|c|c|c|c|c|}
\hline Name of the flower & $\begin{array}{l}\text { Number of } \\
\text { Rotational } \\
\text { Symmetry }\end{array}$ & $\begin{array}{c}\text { Rotation Angle } \\
(360 / n)\end{array}$ & Mirror Lines & Unique Mirror Lines & Mirror Presentation \\
\hline Euphorbia milii & 2 & 180 & 2 & 2 & \\
\hline Trillium & 3 & 120 & 3 & 1 & \\
\hline Ixora coccinea & 4 & 90 & 4 & 2 & \\
\hline Catharanthus roseus & 5 & 72 & 5 & 1 & \\
\hline Coccinia & 5 & 72 & 5 & 1 & \\
\hline Duranta erecta & 5 & 72 & 5 & 1 & \\
\hline Barleria cristata & 5 & 72 & 5 & 1 & \\
\hline Adenium & 5 & 72 & 5 & 1 & \\
\hline $\begin{array}{c}\text { Vining Pink } \\
\text { Mandevilla flower }\end{array}$ & 5 & 72 & 5 & 1 & \\
\hline Murrayapaniculata & 6 & 60 & 6 & 2 & \\
\hline
\end{tabular}




\section{Conclusion}

Maximum flower shows five-fold symmetry. Nature always accepts any kind of symmetry. The descriptions above indicate that symmetry and shape are related to structure. The details symmetry analysis on flowers is very important in flowering plant molecular phylogenetic research analysis and studies of character evolution, additionally as elaborated flower biological process genetic studies in numerous species.

\section{References}

1. http://jwilson.coe.uga.edu/EMT668/EMAT6680.2002.Fall/ Nazarewicz/7210_final_2/7210_Project
2. http://thebeautifulbuildingok.blogspot.com/2012/06/10-beautifulbut-rare-three-petal.html

3. https://math.stackexchange.com/questions/777100/what-is-aunique-mirror-line-of-symmetry

4. https://en.wikipedia.org/wiki/Coccinia

5. Hileman LC (2014) Trends in Flower Symmetry Evolution Revealed through Phylogenetic and Developmental Genetic Advances. Phil Trans R Soc B 369(1648): 20130348.

6. Endress PK (1999) Symmetry in Flowers: Diversity and Evolution. Int J Plant Sci 160(6 Suppl.): S3-S23.
This work is licensed under Creative Commons Attribution 4.0 License

DOI: 10.19080/CTBEB.2018.16.555941 